\section{Prostaglandins as Mediators of Reactive Hyperaemia in Kidney}

SeVERAL mechanisms have been proposed to account for the reactive hyperaemia which follows arterial occlusion in the kidney, including the intrarenal production of a vasodilator substance $^{1,2}$. Recent work shows that the local generation of a prostaglandin can cause vasodilatation in the kidney ${ }^{3,4}$ and can contribute to autoregulation of renal blood flow ${ }^{5,6}$. We have therefore used a prostaglandin synthetase inhibitor, indomethacin ${ }^{7}$, to test whether the reactive hyperaemia which follows release of renal artery occlusion is mediated by a prostaglandin mechanism.

Ten mongrel dogs of either sex weighing 9.5-28 kg, were anaesthetised with pentobarbitone sodium $\left(30 \mathrm{mg} \mathrm{kg}^{-1}\right)$ and ventilated with a respiratory pump. Systemic blood pressure was measured with a Statham pressure transducer from a femoral or brachial artery. The left kidney was exposed by transabdominal incision and the renal artery was isolated to a length of 4-5 cm. Care was taken to minimise manipulation of the kidney and of the renal nerves. Renal blood flow was measured with an electromagnetic flowmeter (Biotronix, Model BL-61 0). The ureters were cannulated and urine output was measured with drop counters. Renal blood flow, urine output and systemic blood pressure were recorded continuously on a Beckman Type S-II Dynograph.

The renal artery was occluded with a clamp placed distally to the flowmeter probe. Occlusion was maintained for $3 \mathrm{~min}$ and then released. After reproducible effects had been obtained, an intravenous infusion of $0.9 \% \mathrm{NaCl}$ was given in a dose of about $30 \mathrm{ml} \mathrm{kg}^{-1}$. The fluid volume of the animal was then maintained constant by saline injected from an automatic syringe which replaced each $\mathrm{ml}$ of urine excreted with an equivalent amount of saline. Occlusion of the renal artery was then repeated before and after indomethacin (1-5 mg kg-1 intravenously). In three experiments sodium content was measured in the urine samples collected in 10-15 min intervals before and after indomethacin administration.

The rate of blood flow through the kidney varied from 100 $400 \mathrm{ml} \mathrm{min}{ }^{-1}$ in different experiments. The patterns of flow changes after the release of arterial occlusion differed between animals. There was always an initial brief overshoot of flow which was followed either by a gradually reducing phase of increased flow or by a transient decrease before the flow returned to the pre-occlusion value. After saline load, the brief overshoot was higher and the phase of increased flow was potentiated and prolonged. The transient decrease in flow which followed release of occlusion in some experiments was also abolished. Indomethacin administration induced a decrease in resting renal blood flow, urine output and sodium excretion and a reduction of the reactive hyperaemia which followed release of occlusion. The reduction in resting flow ranged from $5 \%$ to $24 \%$ of the initial value. The average decrease following administration of 1,2 or $5 \mathrm{mg} \mathrm{kg}^{-1}$ of indomethacin was $9 \%, 13 \%$ and $18 \%$ respectively. Urine output decreased in all animals and the sodium content of the urine was reduced from $7 \%$ to $25 \%$ within $1 \mathrm{~h}$ after indomethacin administration.

The reactive hyperaemia following release of renal arterial occlusion was decreased or abolished after indomethacin (Fig. 1). Although the initial brief overshoot was not much reduced, the slower phase of increased flow was either reduced (five experiments) or completely abolished (four experiments). In one animal, which interestingly had a raised blood pressure $(175 / 100 \mathrm{~mm} \mathrm{Hg})$, indomethacin did not change the reactive hyperaemia.

In the anaesthetised dog, there is a continuous output of a prostaglandin into the renal vein ${ }^{6,8}$. The output is increased by various manoeuvres, including ischaemia ${ }^{9}$ and reduction in perfusion pressure ${ }^{6}$ and the prostaglandin has been identified as mainly $E_{2}$ (ref. 9), which is a potent renal vasodilator.

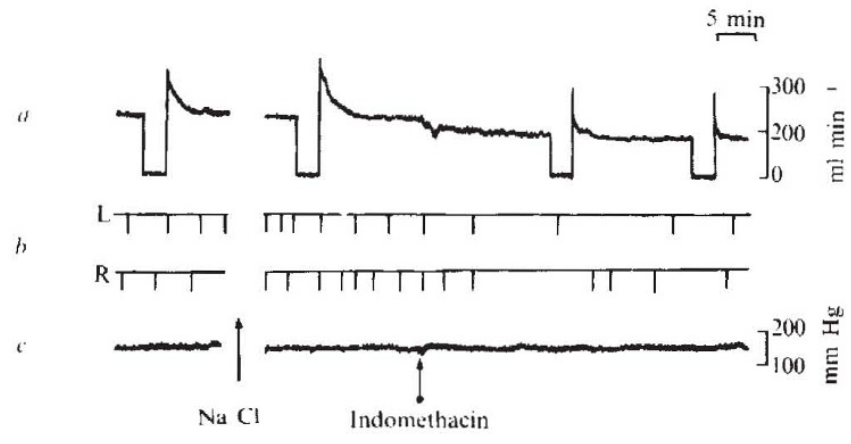

Fig. 1 Effects of intravenous saline and indomethacin on the post-occlusive hyperaemia in the kidney. $a$, Renal blood flow of the left kidney; $b$, urine output $(\mathrm{ml})$ from each kidney; and, $c$, blood pressure of a $9 \mathrm{~kg}$ female dog. Each period of occlusion ( $3 \mathrm{~min}$ ) was followed by a hyperaemia, the magnitude of which was increased by intravenous saline $(30 \mathrm{ml} \mathrm{kg}-1)$. After indomethacin ( $2 \mathrm{mg} \mathrm{kg}^{-1}$ intravenously) resting renal blood flow decreased, as did urine flow. All but the fast phase of postocclusive hyperaemia was abolished.

Indomethacin reduces renal blood flow and abolishes the prostaglandin output ${ }^{3,6}$. Our experiments have now shown that the reactive hyperaemia which follows renal artery occlusion is also reduced or abolished by indomethacin. Thus, the most likely interpretation of our results is that the reactive hyperaemia is at least partially due to a prostaglandin mechanism. It could be that during cessation of blood flow, the basal output of prostaglandin continues within the kidney, or that the ischaemia which is produced actually increases the output. In either situation, the increased concentration of prostaglandin would cause increased vasodilatation, which would express itself by the reactive hyperaemia when blood flow is re-established. As the increased concentration is washed away by the blood, so the vessels would return to their previous tone.

The increase in the reactive hyperaemia which followed saline infusion into the dog also supports this mechanism, for prostaglandins are natriuretic ${ }^{10}$ and saline load increases renal prostaglandin output ${ }^{11}$. Thus, an increased prostaglandin production in the kidney may contribute to the increase in urine flow which follows the saline load.

\section{K. Herbaczynska-Cedro*}

$$
\text { J. R. VANE } \dagger
$$

Department of Pharmacology,

Institute of Basic Medical Sciences,

Royal College of Surgeons of England,

Lincoln's Inn Fields,

London, WC $2 A 3 P N$

Received October 12; revised November 16, 1973.

* Present address: Experimental and Clinical Medical Research Centre, Polish Academy of Sciences, Dwarkowa 3, Warsaw.

$\dagger$ Present address: Wellcome Research Laboratories, Langley Court, Beckenham, Kent.

${ }^{1}$ Hinshaw, L. B., Page, B. B., Brake, C. M., and Emerson, T. E., Am. J. Physiol., 205, 1033 (1963).

2 Honda, N., Aizawa, C., and Yosnitoshi, Y., Am. J. Physiol., 215, 190 (1968).

${ }^{3}$ Aiken, J. W., and Vane, J. R., J. Pharm. exp. Ther., 184, 678 (1973).

${ }^{4}$ Lonigro, A. J., Terragno, N. A., Malik, K. U., and McGiff, J. C., J. lab. clin. Med., 78, 1016 (1971).

5 Herbaczynska-Cedro, K., and Vane, J. R., Proc. fifth int pharmac. Congress. Abstr., p. 596.

${ }^{6}$ Herbaczynska-Cedro, K., and Vane, J. R., Circ. Res., 33, 428 (1973).

7 Vane, J. R., Nature new Biol., 231, 232 (1971).

8 Lonigro, A. J., Itskovitz, H. D., Crowshaw, K., and McGiff, J. C., Circ. Res., 32, 1712 (1973).

9 McGiff, J. C., Crowshaw, K., Terragno, N. A., Lonigro, A. J., Strand, J. C., Williamson, M. A., Lee, J. B., and Ng, K. K. F., Circ. Res., 27, 765 (1970),

10 Lee, J. B., Prostaglandins, 3, 551 (1973).

11 Papanicolaou, N., Experientia, 28, 275 (1972). 